\title{
Knowledge exchange and ethnic networks of clustered small-scale enterprises in Africa: A case study of furniture cluster in Tanzania
}

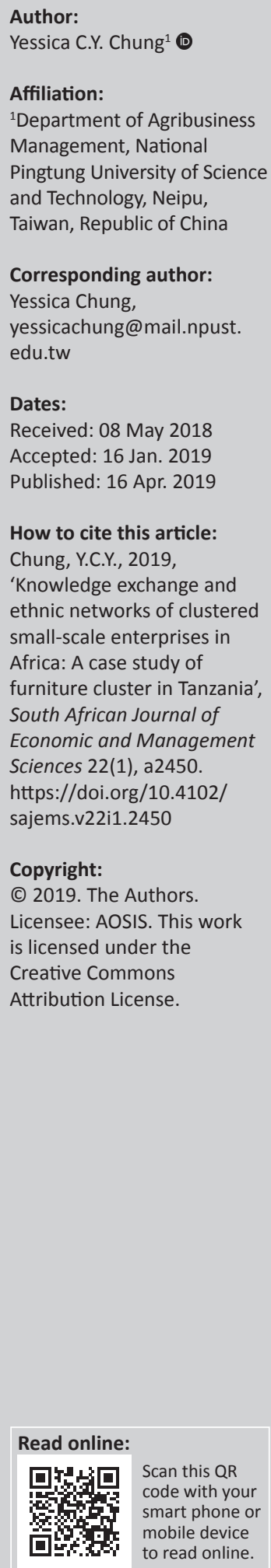

Background: Industrial clusters remain at the initial stage in the sub-Saharan Africa (SSA) region. They produce low-quality and similar products that are poorly innovative and therefore unable to expand. Ethnicity is a characteristic imprint of SSA clusters. However, little research has been done on SSA industrial clusters being able to explore ethnic effects on cluster development, in particular the cases where ethnic majority is over-presented.

Aim: This study aims to investigate the effect of ethnic network between ethnic majority and minority on knowledge exchange in clustered micro and small-scale enterprises in Africa.

Setting: This study was undertaken in the furniture cluster located in Arusha City, Tanzania, which has striking features in its ethnic composition of a dominant ethnic majority and a variety of ethnic minorities. A census survey on the 234 clustered furniture enterprises was conducted to collect comprehensive information on production skill and ethnicity at individual level.

Methods: Probit and ordered probit models are employed to analyse the difference in manufacturing skill between the ethnic majority and minority as well as the inter-ethnic and intra-ethnic enterprises.

Results: Results show a positive and significant effect of the strength of the ethnic networks in having advanced skills in furniture production; particularly evident is the skill that is governed by enterprises' own capability rather than production facilities. Comparing technological skills between the inter-ethnic enterprises and intra-ethnic enterprises, the former are more likely to share similar manufacturing technology with each other than the latter. While individuals in the ethnic majority resemble uniform manufacturing techniques in higherpriced furniture work, the ethnic minority exhibits a similarity in producing common goods.

Conclusion: Ethnic network is a predictor of technological skills of clustered producers in the SSA region. However, the ethnic network effect can only influence the skills that are apparently observed and barely affects capital-intensive technology. These findings indicate the significance of the ethnic networking effect in knowledge exchange in Africa, but remain ineffective in overcoming capital constraints.

Keywords: Ethnic network; ethnic majority; knowledge exchange; industrial cluster; sub-Saharan Africa.

\section{Introduction}

The informal economy contributes to about $40 \%$ of gross domestic product (GDP) and created more than $70 \%$ of employment in the sub-Saharan Africa (SSA) region (International Labour Office [ILO] 2013; Schneider \& Enste 2000; The World Bank 2004). Businesses in the informal economy are mostly micro and small-scale enterprises (MSEs), and geographically concentrated in certain fields in the SSA region. SSA MSEs congregate in industrial clusters, fairly similar to MSEs worldwide, to have better access to industrial information, suppliers and labourers (David \& Rosenbloom 1990; Kelly \& Hageman 1999; Krugman 1991; Marshall \& Marshall 1920; Porter 1990; Swann, Prevezer \& Stout 1998). The distinctive difference between SSA industrial clusters and those in other regions is the ethnic context.

Social capital and innovation system are the two important factors affecting regional development (Braczyk, Cooke \& Heidenreich 1998; Fukuyama 1995). These two seemingly parallel factors are intertwined in cluster development. Innovation evolves frequent knowledge exchange, which 
contributes to cluster development (Kelly \& Hageman 1999; Kesidou \& Romijn 2008; Paci \& Usai 1999). However, knowledge exchange does not happen randomly, but occurs within a group or between two persons who have a relationship of trust. The maintenance of trust consequently builds up social capital and networks in a community or region, which is the key factor predicting the success of the region and companies (Audretsch 1998; Breschi \& Lissoni 2001; Crespo, Suire \& Vicente 2013; Fukuyama 1995; Henderson 1997; Li et al. 2013; Powell, Koput \& Smith-Doerr 1996).

Most industrial clusters remain at the initial stage in the SSA region. They produce low-quality and similar products that are poorly innovative, and therefore end up without expansion (McCormick 1999). Ethnicity leaves a characteristic imprint on SSA's development. However, diverse ethnicity has an adverse effect on its economy (Easterly \& Levine 1997). There is a lower trust relationship between ethnic groups and even hostile attitudes to each other, particularly in the case of the presence of the ethnic majority, which has privileges and gains control of resources. Nevertheless, little research has been done on SSA industrial clusters being able to explore ethnic effects on cluster development in which the ethnic majority is over-presented.

This study explicitly focuses on the impact of an ethnic network on clustered MSEs' manufacturing skills in SSA, particularly with regard to the presence of an ethnic majority. The study site, which is the furniture cluster located in the city of Arusha, Tanzania, has striking features in its ethnic composition of a dominant ethnic majority and a variety of ethnic minorities. This study collected comprehensive information on production technology and ethnicity at individual level from a census survey of 234 clustered furniture enterprises. Empirical results show that ethnicity is the predictor of MSEs' manufacturing skills in the cluster. The strength of ethnic networks contributes to the acquisition of advanced techniques. However, the ethnic networking effect cannot overcome capital constraints. It cannot impact on the skills that cannot be apparently observed but necessitate capital-intensive facilities. Accordingly, key contributions of this study help account for knowledge diffusion and breakdown of inter-ethnic exchange channels in SSA clusters.

The remainder of the article is organised as follows: the section 'Industrial clusters and social networks' documents literature reviews on the industrial cluster and clustered ethnic networks. The section 'The furniture cluster in Arusha' introduces the study site, which is the furniture industrial cluster located in Arusha City, Tanzania. The section 'Methodology and data' introduces probit models and the data. Empirical results are presented in the section of the same name. Lastly, the section 'Conclusion and policy implication' provides conclusions and policy suggestions.

\section{Industrial clusters and social networks}

Industrial clusters fascinate economists investigating the formation, development and economic effect of industrial clusters on national economy. In practice, they enlighten authorities to strike industrial cluster relevant strategies for shaping national competitiveness. Industrial cluster refers to a geographic concentration of interconnected companies and institutions in a particular field (Porter 1998). Industrial entities agglomerating in a certain area allures a skilled labour force, reducing transaction cost and accelerating knowledge creation, innovation and spillover among the involved participants. The extent of the economics of scale derived from the agglomeration of economy generates positive externalities to the national economy and heightens the strength of the country to compete in global markets (David \& Rosenbloom 1990; Kelly \& Hageman 1999; Ketels 2013; Krugman 1991; Marshall 1920; Marshall \& Marshall 1920; Porter 1990; Sonobe \& Otsuka 2006; Swann et al. 1998). Knowledge creation and exchange in clusters that receive the largest attention in cluster literature on knowledge exchange are the foundation of innovation and the key driving force of a cluster's development.

Knowledge spillover has occupied the central position in industrial cluster research. Research is devoted to exploring the knowledge creation and innovation process, catalysis and the channels of knowledge spillover (Rivera, Soderstrom \& Uzzi 2010). Scholars' consensus through face-to-face interactions among clustered firms is that clusters enhance mutual trust and endow clustered firms with privileges in acquiring industry-specific information compared with their cluster-outside counterparts. Marshall (1920) explicitly depicted the prominent advantage of being clustered: 'the mysteries of trade become no mysteries in cluster; but are as it were in the air'. Similar firms with divergent knowledge gather together to solve the same problems, and the rivalrous relationship motivates them to continuously monitor and compete with each other, which results in knowledge creation and innovation (Porter 1990, 1998). Through knowledge exchange, clustered small companies reduce uncertainty and risk entailed in their business routine and production (Chung \& Kalnins 2001; Folta, Cooper \& Baik 2006; Sorenson \& Audia 2000; Stuart \& Sorenson 2003) and keep up with industry trends without further endeavours (Brown \& Duguid 1991).

However, studies have divergent views in terms of the types of knowledge to be exchanged. A strand of studies asserts that the knowledge exchange between clustered companies is limited to the non-technological level, whereas specialised knowledge should transfer through formal contracts. Patent transferring is a case in point, as clustered knowledge sharing in business activity is not a natural phenomenon. Clustered companies intrinsically compete rather than collaborate with each other due to the fact that recipients' knowledge learning and imitation, in turn, hurt transfer profits (Hoang \& Antoncic 2003; Mesquita 2007; Shaver \& Flyer 2000). Another strand of studies on industrial clusters enriches the research in exploring the relationship between knowledge transfers, recipients and the channels. Companies can gain knowledge diffusion from their competitors, suppliers and customers by having joint technical meetings, interpersonal communication 
and patent disclosure (Harabi 1997; Von Hippel 1988). Nevertheless, Krugman (1991) surrendered the possibility of comprehending knowledge exchange because:

... knowledge flows are invisible; they leave no paper trail by which they may be measured and tracked, and there is nothing to prevent the theorist from assuming anything about them that she likes (p. 53).

Musteen, Francis and Datta (2010) gave a clue for research on discriminating companies' knowledge receiving and transferring channels by looking at the firm's size: large-scale companies tend to use contracts while small and medium enterprises (SMEs) rely more on social networks. Moreover, it is undeniable that those channels are established under mutual trust between recipients. Even formal business contracts are initiated by two people who have a relationship based on trust.

Another issue is how to establish trust in clustered businesses. Basically, trust is associated with ethnicity and linguistics (Leigh 2006). Inborn relationships such as kinship ties and inherent ethnic relations outweigh acquired trust in business activities. Ethnicity can act as a natural social bond forging reciprocal trust among group members. Greif (1993) illustrated the mechanism by modeling the coalition among ethnically Jewish Maghribi traders in the western Mediterranean. He stated that the agency relation between merchants and agents was governed by a reputation-based trust mechanism, in which inter-ethnic culture and trust substitute for a contract by specifying ex ante group rules of behaviour and practising ex post group punishment. This means that inter-ethnic trust disciplines ethnic members not to disclose unapproved information to outsiders, otherwise the member will be eternally ostracised and ejected by the ethnic group. This is considered to be an effective way to attain ethnic prosperity in countries with lower property rights protection. In such countries, ethnic group members are encouraged to have a bigger vision and therefore perform altruism that is necessary when group members imperceptibly sacrifice and minimise self-interest. Thus, some information is secured and only circulated within the ethnic traders' group.

The significance of ethnic networking in clusters is limited but being proved in literature. Liang (1999) showed that ethnic networks serve as a wirepuller for outsiders to enter clusters in a regulated market. In the early 1980s, when China remained a closed economy, Taiwanese and Hong Kong companies were able to access the Shenzhen special economic zone owing to their ethnicity. In addition, Zaheer, Lamin and Subramani (2009) looked at clustered businesses' location decisions across 11 clusters in India, and confirmed an ethnic network of CEOs that surpassed cluster characteristics as the key factor predicting companies' locational choice. Zaheer et al. (2009) explained that the reason behind this is that social networks reduce outsiders' liability of being outsiders who have a lower understanding of the local market. Without ethnic networks, outsider businesses are less likely to reap clustered economic benefits. Clustered enterprises in
SSA are not the exceptions. Muto, Chung and Shimikoshi (2011) confirmed that Tanzanian MSEs tend to locate their business near their ethnic members. Kristiansen (2004) also mentioned the impact of personal networks information on entrepreneurial success in the Tanzanian context.

The aforementioned literature confirmed the importance of inter-group trust in business information exchange. However, the intra-ethnic discrepancy in clusters remains unknown. Intra-ethnic disparity can cause hostility toward other groups and living distances (Dustmann \& Preston 2001). It is because inter-ethnic trust erects a barrier preventing ex-ethnic groups sharing resources in business finance and information and, in turn, ethnic discrepancy harms a nation's economic development, particularly in the overwhelming presence of a dominant ethnic majority. Easterly and Levine (1997) found African ethnic fragmentation adversely affecting its economic growth by $30 \%$ compared with other countries. Studies prove that the ethnic majority has better access to financing and information.

Few studies have been able to answer the case of the presence of a dominant ethnic group within clusters despite its worldwide prevalence. This results from the difficulties in identification of individuals' knowledge exchange without codified documents. It is more evident in SSA. Numerous studies have investigated the technological transfer from advanced economies to less developed countries, in particular foreign direct investment (FDI)-led knowledge spillover from exporting countries to their destination countries (Hoang \& Antoncic 2003; Swenson 2008; Todo \& Miyamoto 2006). Most studies view research and development expenditures and patent citations as the best indicators of technology diffusion (AlAzzawi 2011; Jaffe, Trajtenberg \& Henderson 1993; Keller 2002; Kelly \& Hageman 1999). However, these codified proxies for knowledge transfers or diffusions are not applicable to Africa where production units are informal sectors and in which data are not coded. Conley and Udry (2010) addressed the difficulty and offered a clue for African study. They collected data from the 'information' neighbourhoods of Ghana pineapple farmers and compared the similarity in fertiliser use between individual pineapple farmers and their 'information' neighbours. They found that farmers adjust their inputs to align with their 'information' neighbours who have been successful in previous periods.

\section{The furniture cluster in Arusha}

The study site Arusha City is the biggest city of the Arusha region which is the largest among the 31 regions of Tanzania. The area size of Arusha City is $82.5 \mathrm{~km}^{2}$ and the population is about 133000 (2012 census). Geographically, it is located in northern Tanzania, close to the border with Kenya. The city is at the foot of Mount Meru, surrounded by Mt Kilimanjaro, and the Serengeti and Ngorongoro national parks. The agreeable weather with an average temperature of 25 degrees and relative humidity of $82 \%$, as well as abundant forest resources, favour the wooden furniture industry. 
The wooden furniture industry consists of small-scale enterprises, geographically gathering in five areas of Arusha City: the Nairobi-Moshi area, industrial area, Sokoine area, Dodoma Road area, and city centre area. As of the 2007 census survey on the cluster, conducted by Japan International Cooperation Agency (JICA) using personal questionnaires, five sub-clusters account for $34 \%, 25 \%, 16 \%, 13 \%$, and $12 \%$ of the total number of 234 enterprises. The cluster as a whole mainly produces necessities for the locals; the three most observed products are beds, couches and cupboards. Under the scant formal learning sources and FDI in the area, it is not surprising that Arusha MSEs are prone to learn through personal ties.

Tanzania has more than 120 ethnic groups, among which Sukuma is the largest, accounting for an estimated 3.2 million members, representing $10 \%-13 \%$ of the total population, followed by Nyamwezi. In the Arusha region, Iraqw, Arusha, Maasai, Meru and Barbaig are the main ethnic groups (according to the report of Arusha region socio-economic profile 1998). The furniture cluster in Arusha City can be described as a microcosm of most African countries that are ethnically diverse. It comprises 35 ethnic groups with the overwhelming ethnic majority Chagga and a variety of ethnic minorities. Chagga accounts for $41 \%$ of the total furniture entrepreneurs, triple the size of the second largest Pare ethnic group (12\%) in the cluster (see Figure 1). Despite the expansion of the cluster, Chagga remains the majority. According to interviewees' statements, the expansion results from the rising demand of the economic boom of construction and the hotel industries. Compared with 3\% of total clustered enterprises for the Arusha indigenous tribes, the Maasai and Arusha, the overrepresented number of Chagga in the cluster proves its strength in the industry, based on the fact that Chagga is an ethnic minority in the Arusha region.

Based on the site information revealed by the interviewed enterprises, the Chagga ethnic group has been known for their deftness in customer-luring and business connections with developed countries through religious meetings. Exploiting the connections, they more easily acquire specialised catalogues and books than others. The legacy of racial segregation for eight decades during the colonial period appears to slightly add to the ethnic separation, but ethnically distinctive cultures weigh intrinsically and heavily on ethnic-based communities and economies. The colonial period can be dated back to the 1880s when Tanzania was a German colony until 1919, when it became a British colony from the end of World War I to 1961. During the colonial period, Germany established a rigid colonial racial hierarchy of Europeans, Asians, Arabs and Africans in Tanzania, and

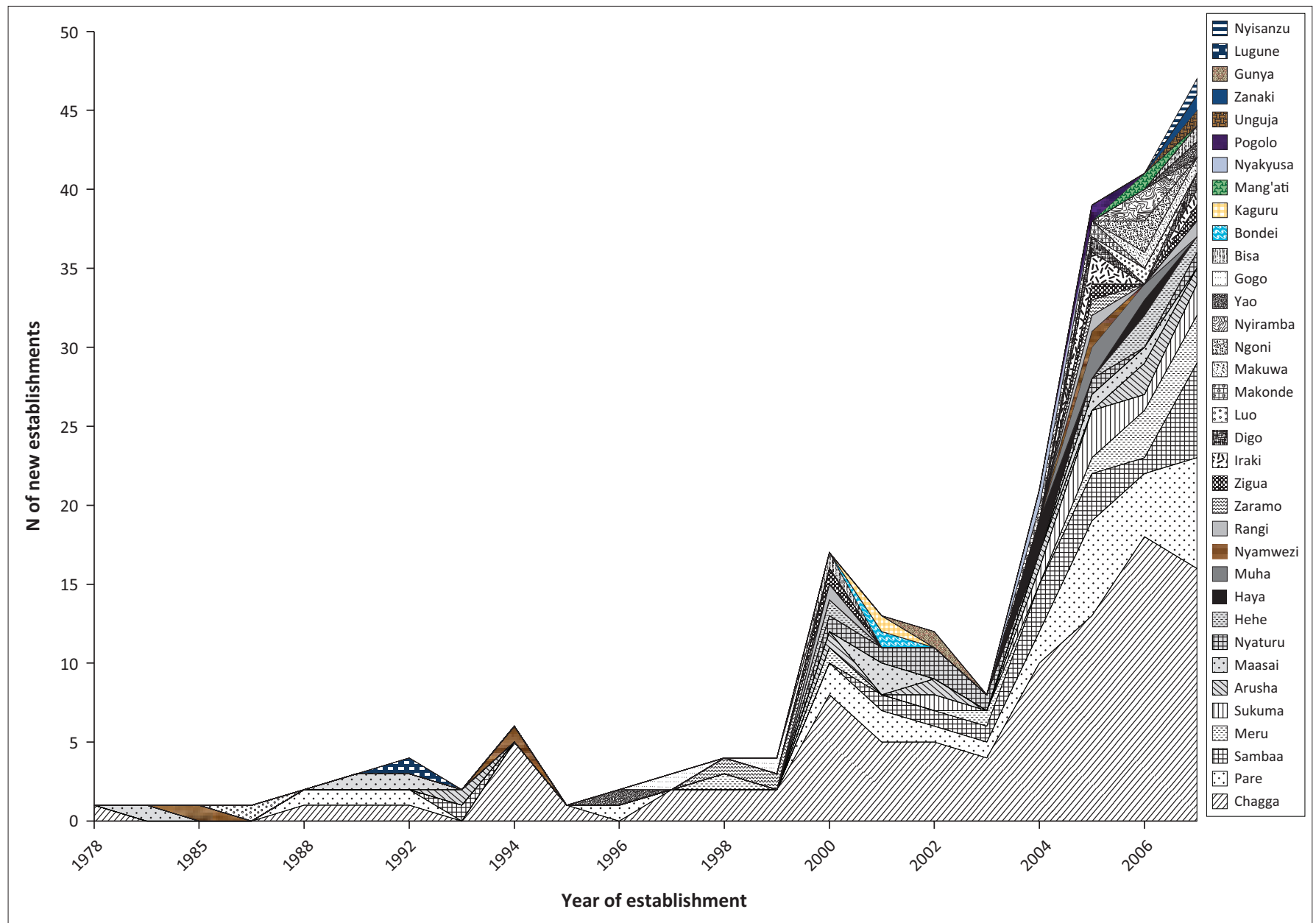

FIGURE 1: Furniture producers in the cluster by ethnic group. 
Britain maintained the German policy of this racial hierarchy. The racial segregation policy led each ethnic group to have its own schools, hospitals and places of entertainment. Mixed racial activities were rarely observed. However, the policy no longer exists; nowadays all ethnic groups officially speak English and Swahili.

\section{Furniture production}

Before exploring the Arusha MSE learning path, it is important to know its furniture production process and entities involved. The supply chain of the clustered furniture industry encompasses timber yards, furniture workshops, machining, metal materials and cart shops. As the industry division of labour is half-fledged, furniture enterprises carry out the major processing and logistic activities of furniture production from timber seasoning, and design, to component assembly, marketing and transportation (see Figure 2).

Among all, timber desiccation treatment and assembly are the two important processes in furniture production. With the first process, timber desiccation is highly related to temperature and humidity. Wood in natural form is sensitively responsive to moisture, and its dimensions change imperceptibly with moisture content causing expansion or shrinkage which results in damage to the final goods. A conditioned storage room is necessary for furniture companies. However, temperature controllers are not affordable for Arushan enterprises. Thus, the timber seasoning process is heavily inhibited by environmental circumstances and enterprises' care. Some producers are keen on the process and carefully store timbers, while some disperse timber outdoors. The widely used measure of moisture content of wooden furniture is the Equilibrium Moisture Content (EMC) indicator. The optimisation of EMC varies with its location; the optimum EMC for Arusha is 2.
On the other hand, the assembly process is fully governed by the producers' skills. Basically, local producers use four tools for component assembly: wood, screw, nail and glue. A mortise and tenon joint, exclusively using wood, is considered to be a sophisticated approach. It is followed by using metal, such as screw and nail joints. Lastly, gluing is the easiest and cheapest approach. Furniture assembled with mortise and tenon joints, compared to butt joints in which pieces of wood are joined using screws, nails, or glue, is considered a high value-added item. Creating mortise and tenon joints is time-consuming and requires skill; thus producers are less likely to use it on low-priced products. The ranking rules of assembly skills are: (1) joints including mortise joints which are ranked higher than those using screws, (2) joints including nails which are ranked below screwed joints, (3) joints with glue which are inferior to those using nails. Accordingly, a higher ranking indicates a superior manufacturing technique. The ranks of 15 wood-joining techniques are listed in Appendix 1.

To trace the evidence on mutual knowledge exchange of specialised skills between two SMEs, the data on individual SMEs' technologies applied in final products are required. However, this is daunting work and the primary challenge for an empirical study on the topic in SSA, where knowledge exchange is rarely codified. This study, thus, conducted a labour- and cost-intensive survey for collecting comprehensive data pertaining to two important production techniques in the furniture industry: timber seasoning and assembly skills at the individual level. The timber seasoning skill was evaluated by the moisture content in three main products using a moisture meter HM52O (MOCO-2) and timber assembly skill was tested by a thorough inspection of the joints of three main products. For each product, at least three spots were measured. For example, the moisture contents of four legs and the plank in a bed were measured. In addition, the location of enterprises was identified by global positioning

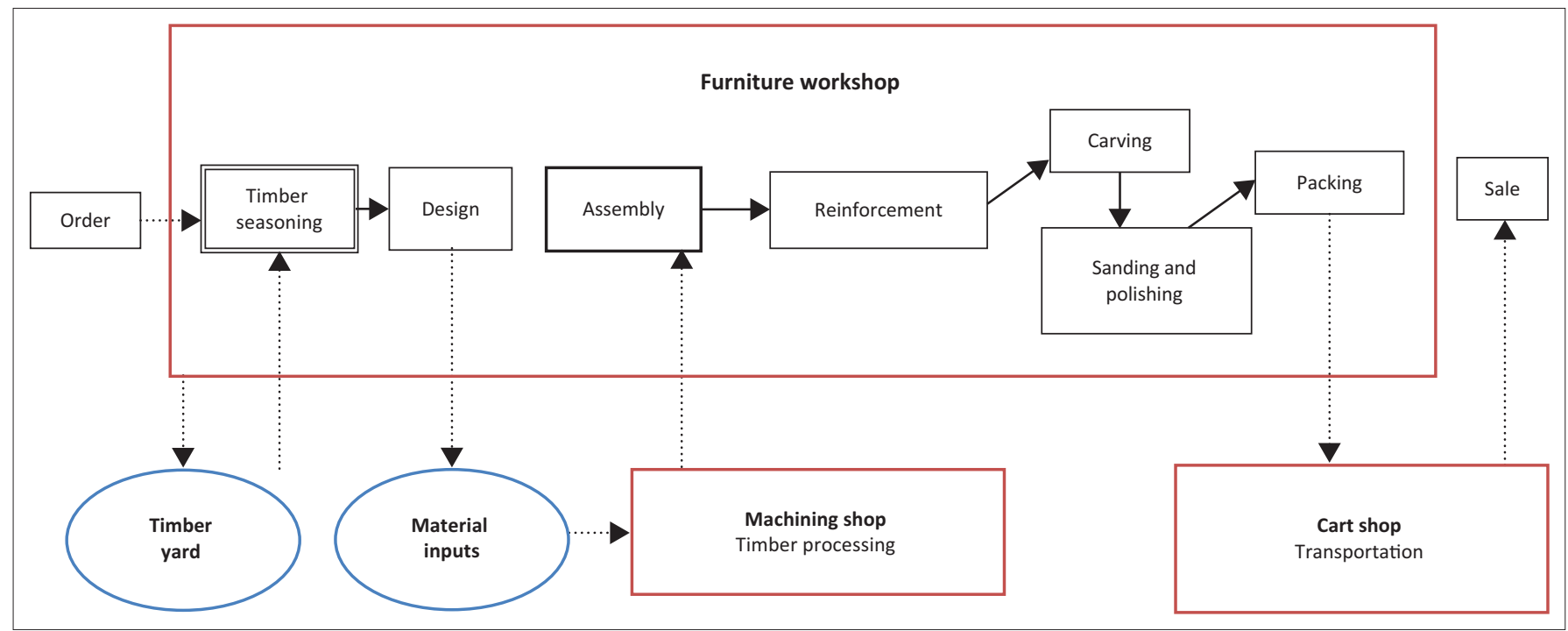

Note: Solid lines represent activities carried out by furniture workshops. Dotted lines represent outsourcing activities.

FIGURE 2: Integrated production organisation. 
system (GPS) equipment and the distances between two enterprises were calculated by geographic information system (GIS) software.

The clustered ethnic composition, one dominant ethnic group and a variety of minorities, suits this study to examine two hypotheses. Firstly, the ethnic homogenous effect: ethnicfellow producers possess similar manufacturing skills. Secondly, the network strength effect: a bigger ethnic group (majority) is more likely to have advanced skills than small ethnic groups (minority).

\section{Methodology and data Probit model}

This study used the probit model with dyadic data to examine if two ethnic enterprises exhibited the same manufacturing techniques and if the number of ethnic members was a predictor of advanced technological skills. The latent variable, knowledge exchange $y_{i j}^{*}$ is calculated as follows in Equation 1:

$y_{i j}^{*}=\theta E_{i j}+\beta x_{i j}+e_{i j}$

[Eqn 1]

$E_{i j}$ is the ethnicity variable, taking a value of 1 if producers $i$ and $j$ are from the same ethnic group; otherwise it is 0 . A set of control variables $x_{i j}$ including geographical distance captures characteristics between enterprises $i$ and $j . e_{i j}$ is an error term independent of explanatory variables $E_{i j}$ and $x_{i j}$ Knowledge exchange is unobservable and untraceable. In practice, $y_{i j}$ is measured by the similarity in technology between $i$ and $j$ in Equation 2:

$y_{i j}= \begin{cases}1 & \text { if } y_{i j}^{*}>0 \\ 0 & \text { if } y_{i j}^{*} \leq 0\end{cases}$

If knowledge exchange $y_{i j}^{*}$ between producers $i$ and $j$ reaches a certain frequency, their manufacturing skills $y_{i j}$ are similar, and take a value of 1 ; otherwise it is 0 .

The distribution of similarity in skills between two producers $y_{i j}$ given $E_{i j}$ and $x_{i j}$ are as follows in Equation 3:

$$
\begin{aligned}
p\left(y_{i j}=1 \mid x_{i j}\right) & =p\left(y_{i j}^{*}>0 \mid x_{i j}\right)=p\left(\theta E_{i j}+\beta X_{i j}+e_{i j}>0 \mid x_{i j}\right) \\
& =p\left(e_{i j}>-\beta x_{i j} \mid x_{i j}\right)=1-\Phi\left(-\beta x_{i j}\right)=\Phi\left(\beta x_{i j}\right)
\end{aligned}
$$

[Eqn 3]

$\Phi($.$) denotes the standard normal cumulative distribution$ function. Similarly, as seen in Equation 4, the probability of non-similarity in technology between two producers is:

$$
p\left(y_{i j}=0 \mid x_{i j}\right)=1-\Phi\left(\beta x_{i j}\right)
$$

Therefore, the density of $y_{i j}$ given $x_{i j}$ is (see Equation 5):

$$
f\left(y \mid x_{i j}\right)=\left[\Phi\left(\beta x_{i j}\right)\right]^{y}\left[1-\Phi\left(\beta x_{i j}\right)\right]^{1-y} \quad y=0,1
$$

The dependent variable is assembly or desiccation skill. Explanatory variables include discrete and continuous independent variables. Discrete variables include the ethnicity, past occupation and training experience variables, and the pair relationship is defined as 1 if producers $i$ and $j$ have the same value; otherwise it is 0 . For continuous independent variables such as schooling years, the absolute values of each of the differentiated and summed values of the variables are added. In terms of interpretation, a negative sign on the differentiated variables denotes assortative matching, indicating that a small difference in the characteristics enhances a likelihood of two producers exhibiting the same skills. On the other hand, a positive sign on the summed values is named level effect, indicating two producers with a higher combined level of the attribute, which are more likely to exhibit the same skill compared to those with a total of a lower level of the attributes. Thus, a negative sign on the differentiated schooling years and, simultaneously, a positive sign on the variable can be interpreted as two producers with a combined high level of schooling years and a small difference between them are more likely to possess the same skill. The total number of entrepreneurs in the cluster is 234 , so there are $234 \times \frac{233}{2}=27261$ unique enterprise pairs in the data. Standard errors are adjusted to be robust to heteroscedasticity.

\section{Data}

Table 1 summarises the variables used in the analyses. The upper section presents the variables as a whole, and the lower shows the comparison statistics between ethnic majority and minority. In the table, Ethnic strength is calculated as the number of ethnic fellow producers in proximity to each enterpriser. This number is restricted to those within a $1 \mathrm{~km}$ radius. The number of $1 \mathrm{~km}$ is considered to be a reasonable walking distance for enterprises to have a face-toface contact as public transportation is not available in Arusha City. Enterprisers who want to communicate with each other or transport their products walk or use a cart. The statistics show that Ethnic strength ranges from 0 to 17 with a mean of about 2, indicating that a furniture producer averagely has 2 ethnic members located nearby albeit a large difference among enterprises. Four control variables related to enterprises' production skills are included in analyses. Enterprise size is measured as the number of workers and has a mean of five. Schooling years has a mean of 9.53, a level equivalent to ordinary schooling, in which furniture specialisation knowledge has not been taught. Nearly half of the enterprises relied on informal learning, and $49 \%$ of enterprises had no work experience. Spin-offs are said to be one of the important channels of knowledge transfer. Unreported data from the study show that few producers were spin-offs of other private or state-owned furniture factories. A typical clustered furniture producer is portrayed as a male in his 30s who is ordinarily educated, without furniture-relevant work experience. He is able to learn production skills through personal networks while starting up a furniture workshop in the cluster, as he has two ethnic fellows in the vicinity who also act as industrial peers. 
TABLE 1: Data summary.

\begin{tabular}{|c|c|c|c|c|c|c|c|c|}
\hline Variable & Number of observations & Mean & Standard deviation & Minimum & Maximum & Minority & Majority & $t$-test \\
\hline Mortise & 231 & 0.89 & 0.31 & 0.00 & 1 & 0.87 & 0.92 & -0.98 \\
\hline Assembly & 231 & 10.9 & 2.50 & 2.00 & 13 & 10.7 & 11.2 & -1.51 \\
\hline Equilibrium Moisture Content & 223 & 1.79 & 0.14 & 1.17 & 2 & 1.79 & 1.78 & 0.68 \\
\hline Ethnic strength & 234 & 2.32 & 3.38 & 0.00 & 17 & 0.68 & 4.67 & $-10.86 * *$ \\
\hline Number of workers & 234 & 4.61 & 4.05 & 1.00 & 54 & 4.95 & 4.12 & 1.54 \\
\hline Schooling years & 234 & 9.53 & 2.71 & 0.00 & 16 & 9.43 & 9.69 & -0.72 \\
\hline None & - & 0.07 & - & - & - & 6.52 & 7.29 & -0.23 \\
\hline Informal learning & - & 0.49 & - & - & - & 53.62 & 42.71 & $1.64 *$ \\
\hline Formal learning & - & 0.44 & - & - & - & 39.86 & 50.00 & -1.54 \\
\hline Past occupation: & 234 & - & - & - & - & - & - & - \\
\hline None & - & 0.49 & - & - & - & 40.58 & 60.42 & $-2.99 *$ \\
\hline Furniture relevant & - & 0.11 & - & - & - & 13.04 & 9.38 & 0.86 \\
\hline Non-furniture & - & 0.40 & - & - & - & 46.38 & 30.21 & $2.49 *$ \\
\hline
\end{tabular}

$*, p<0.05 ; * *, p<0.01$.

Two measurements are used in terms of assembly skills, mortise and tenon joints (labelled Mortise) and ranking of assembly skills (labelled Assembly). Mortise is a binary dummy equal to 1 if a producer performed mortise in any of his products, otherwise 0; Ranking is a categorical variable ranging from 1 to 15 , representing an ascending order of skills in an assembly. Statistics show that Mortise averages 0.89 , indicating that $89 \%$ of producers can perform this assembly technique, and Ranking averages 10.9, indicating that furniture producers tend to use four joining techniques (mortise joints, screws, nails and glue) all together in furniture work. EMC averages 1.79 with a standard difference of 0.14 , indicating a small difference in EMC among the enterprises.

The statistics in the lower section of Table 1 show a significant difference in learning sources between ethnic minority and majority. The minority receives training through formal apprenticeship programmes, while the majority learns through personal ties. Compared with $41 \%$ of ethnic minorities, a significantly higher number - $60 \%$ - of the majority (Chagga) producers had no work experience. This suggests a piece of evidence on a collaborative learning support system in the majority (Chagga) ethnic group. Within the system, an inexperienced ethnic majority can start up in the cluster acquiring occupational skills. The assembly and desiccations skills exhibit a mixed result: ethnic majority is slightly skilled in furniture assembly, whereas the minority is skilled in timber desiccation. However, both figures are insignificant.

Table 2 presents the statistics on dyadic data used in analysing technology disparity within and across ethnic groups. The ethnic variables include three binary dummies: Ethnicity is defined as 1 if producers $i$ and $j$ share the same mother tongue; Majority equals 1 only if paired producers $i$ and $j$ are in the ethnic majority (Chagga), otherwise, it is 0. Likewise, Minority takes the value of 1 if paired producers are from the same ethnic minority, otherwise, it is 0 . The summary table shows that Ethnicity averages 0.19, Majority is 0.17 and Minority averages about 0.03 . These can be interpreted as the probability of having co-ethnic fellows to exchange knowledge in manufacturing skills for Chagga, which is $17 \%$

\begin{tabular}{|c|c|c|c|c|c|}
\hline $\begin{array}{l}\text { Differences between } \\
\text { I and J }\end{array}$ & $\begin{array}{l}\text { Number of unique } \\
\text { enterprise pairs }\end{array}$ & Mean & Minimum & Maximum & $\begin{array}{l}\text { Standard } \\
\text { deviation }\end{array}$ \\
\hline Ethnicity: & 27261 & 0.19 & 0 & 1 & 0.40 \\
\hline Majority & 27261 & 0.17 & 0 & 1 & 0.37 \\
\hline Minority & 27261 & 0.03 & 0 & 1 & 0.16 \\
\hline Distance $(\mathrm{km})$ & 26335 & 2.89 & 0 & 9.12 & 1.63 \\
\hline Diff-workshop size & 27261 & 2.54 & 0 & 53 & 5.01 \\
\hline Sum-workshop size & 27261 & 6.54 & 0 & 71 & 5.59 \\
\hline Diff-schooling years & 27261 & 2.63 & 0 & 16 & 2.79 \\
\hline Sum-schooling years & 27261 & 19.07 & 0 & 32 & 3.82 \\
\hline Training source & 27261 & 0.44 & 0 & 1 & 0.50 \\
\hline Past occupation & 27261 & 0.41 & 0 & 1 & 0.49 \\
\hline Ranking of assembly skills & 26909 & 0.58 & 0 & 1 & 0.49 \\
\hline EMC & 273653 & 0.15 & 0 & 0.83 & 0.13 \\
\hline
\end{tabular}

EMC, Equilibrium Moisture Content; $\mathrm{km}$, kilometres.

and the number declines to $3 \%$ if the producer is an ethnic minority. Distance is the geographic distance between two workshops and the figure shows the farthest distance between two workshops located in the cluster as $9.12 \mathrm{~km}$ while the closest two workshops are adjacent. Likewise, the other independent variables including Training source and Past occupation take a value of 1 only if producers $i$ and $j$ have the same attribution, otherwise it is 0 . The dependent variables are Ranking of assembly skill and timber desiccation skill (EMC). The former is a binary dummy equal to 1 if paired producers are in the same ranking, the latter is a continuous variable and calculated as absolute value of differentiated EMC between enterprises $i$ and $j$.

\section{Empirical results}

Two aforementioned hypotheses are examined with the results reported in Tables 3 and 4 and Tables 5 and 6 .

\section{Ethnicity and production skills}

Table 3 presents the estimation of the probit model using dyadic ethnicity variables on assembly skills. The dependent variable equals 1 if two producers rank the same in the assembly skills. A positive marginal effect on binary explanatory variables indicates that having the same attributes increases the probability of two enterprises having the same 
TABLE 3: Assembly skill and ethnicity.

\begin{tabular}{|c|c|c|c|c|c|c|c|c|c|c|}
\hline \multirow[t]{2}{*}{ Variable } & \multicolumn{2}{|l|}{ (1) } & \multicolumn{2}{|l|}{ (2) } & \multicolumn{2}{|c|}{ Sofa } & \multicolumn{2}{|c|}{ Bed } & \multicolumn{2}{|c|}{ Dining set } \\
\hline & Marginal effect & z-statistics & Marginal effect & z-statistics & Marginal effect & z-statistics & Marginal effect & z-statistics & Marginal effect & z-statistics \\
\hline Ethnicity: & $0.190 * * *$ & 9.39 & - & - & - & - & - & - & - & - \\
\hline Majority & - & - & $0.244 * * *$ & 11.25 & $0.243 * * *$ & 9.90 & -0.009 & 0.22 & -0.054 & 1.10 \\
\hline Minority & - & - & $-0.126 * * *$ & 2.61 & 0.064 & 1.02 & $0.142 *$ & 1.70 & 0.073 & 0.79 \\
\hline Training source & -0.022 & 1.39 & -0.021 & 1.31 & 0.008 & 0.40 & $0.139 * * *$ & 4.56 & 0.028 & 0.82 \\
\hline Past occupation & $-0.073 * * *$ & 4.50 & $-0.076 * * *$ & 4.73 & 0.005 & 0.25 & -0.021 & 0.68 & $0.349 * * *$ & 10.07 \\
\hline Distance & $0.011 * * *$ & 2.30 & $0.010 * *$ & 1.96 & $0.044 * * *$ & 7.59 & $-0.020 * *$ & 2.05 & $0.037 * * *$ & 3.09 \\
\hline Diff-workshop size & $0.055^{* * * *}$ & 14.21 & $0.055 * * *$ & 14.16 & $0.036 * * *$ & 7.65 & $-0.050 * * *$ & 4.79 & $0.071 * * *$ & 8.61 \\
\hline Sum-workshop size & $-0.054 * * *$ & 14.93 & -0.053 & 14.68 & $-0.022 * * *$ & 5.21 & $-0.036 * * *$ & 4.74 & $-0.050 * * *$ & 6.53 \\
\hline Diff-schooling size & $-0.012 * * *$ & 4.22 & $-0.012 * * *$ & 4.16 & $-0.030 * * *$ & 8.29 & $-0.018^{* * *}$ & 3.27 & -0.009 & 1.36 \\
\hline Sum-schooling size & $0.007 * * *$ & 3.09 & $0.006 * * *$ & 2.85 & $0.017 * * *$ & 6.15 & 0.006 & 1.37 & $0.017 * * *$ & 3.42 \\
\hline Pseudo $\mathrm{R}^{2}$ & 0.0110 & - & 0.0124 & - & 0.0135 & - & 0.0203 & - & 0.0311 & - \\
\hline $\begin{array}{l}\text { Bayesian information } \\
\text { criterion }\end{array}$ & 34901.5 & - & 34860.9 & - & 24109.8 & - & 9417.4 & - & 7026.5 & - \\
\hline
\end{tabular}

Note: Probit model is used, and average marginal effects instead of coefficients are reported. The z-statistics are based on standard error estimates obtained from the robust estimator of variance. $*, p<0.1 ; * *, p<0.05 ; * * *, p<0.01$.

TABLE 4: Desiccation skill and ethnicity.

\begin{tabular}{|c|c|c|c|c|c|c|c|c|c|c|}
\hline \multirow[t]{2}{*}{ Variable } & \multicolumn{2}{|c|}{ (1) } & \multicolumn{2}{|c|}{ (2) } & \multicolumn{2}{|c|}{ Bed } & \multicolumn{2}{|c|}{ Couch } & \multicolumn{2}{|c|}{ Cupboard } \\
\hline & Coefficient & $t$-statistics & Coefficient & $t$-statistics & Coefficient & $t$-statistics & Coefficient & $t$-statistics & Coefficient & $t$-statistics \\
\hline Ethnicity: & 0.018 & 0.91 & - & - & - & - & - & - & - & - \\
\hline Majority & - & - & 0.004 & 0.18 & $0.074 * *$ & 2.46 & -0.121 & 1.61 & 0.018 & 0.19 \\
\hline Minority & - & - & $0.102 * *$ & 2.19 & -0.124 & 1.63 & $0.317^{* *}$ & 1.98 & 0.104 & 0.75 \\
\hline Training source & $-0.030 *$ & 1.89 & $-0.030 *$ & 1.92 & -0.023 & 0.92 & 0.105 & 1.44 & $0.116 * *$ & 2.11 \\
\hline Past occupation & $0.049 * * *$ & 3.09 & $0.049 * * *$ & 3.15 & -0.007 & 0.28 & 0.038 & 0.59 & $0.270 * * *$ & 4.69 \\
\hline Distance & -0.005 & 1.01 & -0.004 & 0.92 & $-0.030 * * *$ & 3.90 & $-0.031^{*}$ & 1.77 & -0.008 & 0.42 \\
\hline Diff-number of workers & $0.014 * * *$ & 4.10 & $0.014 * * *$ & 4.12 & 0.008 & 1.43 & 0.022 & 0.82 & $-0.034 * * *$ & 2.92 \\
\hline Sum-number of workers & -0.005 & 1.53 & -0.005 & 1.61 & -0.004 & 0.67 & -0.033 & 1.58 & $0.048 * * *$ & 4.18 \\
\hline Diff-schooling years & $0.016 * * *$ & 5.57 & $0.016 * * *$ & 5.54 & 0.005 & 0.99 & $0.031 * * *$ & 2.63 & $0.081 * * *$ & 8.49 \\
\hline Sum-schooling years & $-0.014^{* * *}$ & 6.47 & $-0.013 * * *$ & 6.41 & $0.011 * * *$ & 2.95 & 0.011 & 1.10 & $-0.086 * * *$ & 11.07 \\
\hline Adjusted $\mathrm{R}^{2}$ & 0.00501 & - & 0.00513 & - & 0.0033 & - & 0.00745 & - & 0.1 & - \\
\hline Bayesian information criterion & 71195.8 & - & 71202 & - & 28771.8 & - & 4569.9 & - & 4215.5 & - \\
\hline Number of observations & 22753 & - & 22753 & - & 9107 & - & 1425 & - & 1425 & - \\
\hline
\end{tabular}

Note: OLS model is used. The $t$-statistics are based on standard error estimates obtained from the robust estimator of variance.

$*, p<0.1 ; * *, p<0.05 ; * * *, p<0.01$

TABLE 5: Assembly skill and ethnic strength.

\begin{tabular}{|c|c|c|c|c|c|c|c|c|c|c|c|c|}
\hline \multirow[t]{3}{*}{ Variable } & \multicolumn{6}{|c|}{ Mortise (probit model) } & \multicolumn{6}{|c|}{ Assembly (ordered probit model) } \\
\hline & \multicolumn{2}{|r|}{$(1)$} & \multicolumn{2}{|c|}{ (2) } & \multicolumn{2}{|c|}{ (3) } & \multicolumn{2}{|c|}{ (1) } & \multicolumn{2}{|c|}{$(2)$} & \multicolumn{2}{|c|}{ (3) } \\
\hline & $\begin{array}{c}\text { Marginal } \\
\text { effect }\end{array}$ & z-statistics & $\begin{array}{l}\text { Marginal } \\
\text { effect }\end{array}$ & z-statistics & $\begin{array}{l}\text { Marginal } \\
\text { effect }\end{array}$ & z-statistics & Coefficient & z-statistics & Coefficient & z-statistics & Coefficient & z-statistics \\
\hline Ethnic strength & $0.012 * *$ & 1.98 & $0.013 * *$ & 2.01 & $0.014 * *$ & 2.14 & $0.056 * * *$ & 2.74 & $0.059 * * *$ & 2.70 & $0.058 * * *$ & 2.64 \\
\hline Workshop size & - & - & 0.004 & 0.50 & 0.003 & 0.44 & - & - & 0.021 & 0.97 & 0.021 & 0.99 \\
\hline Informal learning & - & - & 0.062 & 0.80 & 0.027 & 0.27 & - & - & 0.086 & 0.26 & 0.127 & 0.30 \\
\hline Formal learning & - & - & 0.048 & 0.64 & 0.039 & 0.39 & - & - & 0.167 & 0.51 & 0.163 & 0.38 \\
\hline Furniture-related job & - & - & 0.044 & 0.85 & 0.041 & 0.80 & - & - & 0.251 & 0.96 & 0.254 & 0.96 \\
\hline Non-furniture-related job & - & - & -0.001 & 0.02 & 0.003 & 0.08 & - & - & 0.067 & 0.35 & 0.061 & 0.32 \\
\hline Schooling years & - & - & 0.012 & 1.40 & 0.012 & 1.47 & - & - & 0.015 & 0.42 & 0.014 & 0.40 \\
\hline $\begin{array}{l}\text { Ethnic strength } \times \text { informal } \\
\text { learning }\end{array}$ & - & - & - & - & 0.074 & 0.79 & - & - & - & - & -0.115 & 0.18 \\
\hline Ethnic strength $\times$ formal training & - & - & - & - & 0.032 & 0.25 & - & - & - & - & -0.016 & 0.03 \\
\hline Pseudo $\mathrm{R}^{2}$ & 0.018 & - & 0.44 & - & 0.055 & - & 0.008 & - & 0.013 & - & 0.015 & - \\
\hline Number of observations & 231 & - & 231 & - & 231 & - & 231 & - & 231 & - & 231 & - \\
\hline
\end{tabular}

Note: Within the source of production skills, not trained is the baseline. Similarly, the benchmark for previous jobs is no work experience. Instead of coefficients, average marginal effects are reported. The z-statistics are based on standard error estimates obtained from the robust estimator of variance.

$*, p<0.1 ; * *, p<0.05 ; * *, p<0.01$. 


\begin{tabular}{|c|c|c|c|c|c|c|}
\hline \multirow[t]{3}{*}{ Variable } & \multicolumn{6}{|c|}{ Equilibrium moisture content (ordinary least squares) } \\
\hline & \multicolumn{2}{|c|}{ (1) } & \multicolumn{2}{|c|}{ (2) } & \multicolumn{2}{|c|}{ (3) } \\
\hline & Coefficient & $t$-statistics & Coefficient & $t$-statistics & Coefficient & $t$-statistics \\
\hline Ethnic strength & 0.001 & 0.44 & -0.002 & 0.27 & -0.007 & 1.98 \\
\hline Workshop size & - & - & $0.019 * * *$ & 4.09 & $0.005^{* * *}$ & 4.89 \\
\hline Informal learning & - & - & $-0.241^{* * *}$ & 2.34 & $-0.085^{* *}$ & 3.86 \\
\hline Formal training & - & - & -0.053 & 0.53 & -0.039 & 1.54 \\
\hline Furniture relevant & - & - & -0.034 & 0.41 & -0.008 & 0.40 \\
\hline Non-furniture & - & - & -0.013 & 0.20 & -0.005 & 0.31 \\
\hline Schooling years & - & - & 0.011 & 0.83 & 0.003 & 0.47 \\
\hline Ethnic strength $\times$ informal learning & - & - & - & - & 0.005 & 1.27 \\
\hline Ethnic strength $\times$ informal training & - & - & - & - & 0.009 & 1.35 \\
\hline _Cons & 1.796 & 170.06 & $3.243^{* * *}$ & 19.92 & $1.821 * * *$ & 30.50 \\
\hline Adjusted $R^{2}$ & -0.004 & - & 0.063 & - & 0.056 & - \\
\hline Bayesian information criterion & -285.5 & - & 286 & - & -297.4 & - \\
\hline
\end{tabular}

Note: The $t$-statistics are based on standard error estimates obtained from the robust estimator of variance.

$*, p<0.1 ; * *, p<0.05 ; * * *, p<0.01$.

level of assembly skill; otherwise it is negative. A positive marginal effect on the summed continuous variables is interpreted as a level effect, indicating a positive relationship between the attributes and the number of links. On the other hand, a negative sign on the absolute value of the differentiated continuous variables is interpreted as an assortative matching, meaning a small difference in the characteristics enhances the likelihood of performing the same skills.

Specification (1) of Table 3 shows a significantly positive sign on Ethnicity, implying that co-ethnic producers are more likely to apply the same assembly skills than ex-ethnic producers. To further understand the difference between the Majority and Minority, two variables are simultaneously included in specification (2). Results show a significant and positive sign for Majority but a negative sign for Minority, indicating that the Chagga-Chagga producers employ similar assembly skills, whereas minority members exhibit different skills. As the skills adapt to change with the products, the sample is divided by product lines and displayed in descending order of the number of observations.

The product sofa, which is regarded as a luxury good by the locals, has a positive and significant marginal effect on Majority and a positive but insignificant result on Minority. In contrast, the product bed, which is a common good, shows opposite results on ethnicity variables from the specification sofa. Results of some products are omitted due to the small number of observations. Overall, these results imply that ethnic Chagga enterprises adopted similar skills in producing higher-priced furniture work, while the ethnic minority used similar techniques in producing lower-valued ones. Table 3 implies that ethnicity and assortative matching of educational background predict the similarity in assembly skills of two clustered MSEs.

Table 4 shows the result of timber desiccation skills by using the ordinary least squares (OLS) model. The dependent variable is the differentiated EMC, the disparity in desiccation skills between two MSEs. Differing from Table 3, a positive coefficient of binary explanatory variables indicates the same attribute that increases the difference in desiccation skills. Ethnicity is anticipated to reduce the difference; thus, a negative value on three ethnicity variables is desired. Differentiated variables, including Distance and Diffvariables, with a positive sign are anticipated, interpreted as similar characteristics of two MSEs which decrease their skill disparity. On the other hand, a negative sign on Sumvariables is interpreted as a level effect.

In specification (1), the estimated marginal effect of Ethnicity is positive but insignificant, which seemingly indicates that ethnicity does not explain MSEs' desiccation skill. Yet, the numbers on Majority and Minority in specification (2) overturns the insignificant association between ethnicity and skill. A positive marginal effect on Minority indicates the ethnic minority MSEs perform differently in the technique. These results imply that the ethnic majority exchanges technological knowledge on higher-priced products while the ethnic minority does so on common goods. The possible reason is that moisture content of timber is more sensitive to the environment than to producers' skill. Given the dearth of temperature-controlled facilities in the area, moisture content is not as easily controlled as the assembly skills. This feature makes it difficult for producers to learn from others.

Tables 3 and 4 prove the ethnic homogenous hypothesis that producers from the same ethnic group are similar in their production skills. Results are stronger and more consistent in timber assembly skills than desiccation skills, which may suggest a weaker effect of ethnicity on the skills requiring precision equipment.

\section{Network strength}

Table 5 presents the results for the network strength hypothesis on having the sophisticated wood-joining techniques, the Mortise and the Assembly techniques. The regressions in the Mortise section were examined using a probit model, and those in the Assembly section were 
examined with an ordered Probit model, in which 15 levels of joint skills were ranked and used as the dependent variable. To facilitate interpretation, the average marginal effect instead of coefficient was reported.

Specification (1) of the Mortise section is a simple version that exclusively includes the Ethnicity variable. The marginal effect of Ethnic networks on performing mortise skills is 0.012 and significant ( $p$-value of 0.01 ), indicating that another ethnic enterprise in proximity is likely to have mortise techniques. Specification (2) adds variables capturing the entrepreneurs' learning background including learning source, work experience and schooling years. Learning source is a dummy in which a non-trained group is the baseline; Past occupation contains none (the baseline), indicating no work experience and Schooling years is a continuous variable. Specification (3) adds interaction terms for ethnic networks and training programmes, which aims to analyse the relationship between network strength and a furniture producer's responsiveness to training in manufacturing techniques, that is, whether a producer with more ethnic members outperformed those without ethnic members after a training programme. In contrast to what was expected, training programmes did not enhance producers' manufacturing skills. The endogeneity bias of self-selection in Schooling years and the dependent variable is often raised, and producers who attempt to produce sophisticated work are more likely to seek higher education. This scenario is less likely to happen in the Arusha context, because none of the producers return to school to learn skills for their furniture business, and few of them graduated from schools with a furniture-related major. Moreover, this study replicated the Mortise section of Table 5 by employing a heteroskedastic probit model; the estimated average marginal effects of ethnic networks increase on average by 0.001 across specifications, and all retain significance at $1 \%$. Therefore, endogeneity bias is not a concern in the study.

The Assembly section obtains similar results as the Mortise section. The estimated average marginal effect on Ethnic networks is positive and significant ( $p$-value of 0.05 ) across specifications (2)-(4), indicating that the Ethnic networks is the principal factor increasing the possibility of acquiring advanced assembly skills. One unit increase in the number of ethnic fellow producers increases the possibility of furniture producers acquiring advanced skill by $1.3 \%$.

Table 6 presents the results of network strength effect on timber desiccation skills. In contrast to that of assembly skills, the average marginal effects of Ethnic strength are insignificant across specifications, indicating that the size of ethnic group has no impact on the skill. However, the skill is positively associated with the scale of workshop. This indicates that the number of workers quantitatively contributes to a higher quality of timber desiccation. This is evident in that the largest workshop with 54 workers in the sample had extremely good performance in terms of timber desiccation, recording EMC values of 2 for all its furniture work. This study infers that the moisture content of timber is heavily contingent on manpower for under-capitalised MSEs in Africa.

Tables 5 and 6 verify ethnic strength impact on advanced skills but the impact is subjected to the one that wholly relies on producers' skills rather than the need for a machine. Together with the findings in Tables 3 and 4 , this study asserts that knowledge sharing in professional skills is the way the ethnic majority Chagga reasserts its dominance in the cluster.

\section{Conclusion and policy implication}

This study examines the ethnic networking effect on technology adoption of clustered producers in SSA. Results imply that ethnic network is a predictor of technological skills of clustered producers in the region. In addition, the ethnic majority shares a similarity in producing higherpriced furniture work, whereas in contrast, the ethnic minority produces common goods. However, the ethnic network effect can only influence the skills that can be apparently observed and barely affects capital-intensive technology. This suggests the limitation of ethnic networks in overcoming capital constraints in the SSA region. This result is similar to the finding of Munshi (2004) that technical learning outcomes strongly depend on the characteristics of the subjects to be learned. Specifically, knowledge learning breaks down if the nature of the technology involved is imperfectly observed due to the complexity. With the same study site, Muto et al. (2011) found that ethnic groups in the cluster chose to locate their workshops close to their ethnic fellows. Chung (2018) revealed that the Chagga ethnic group was deft at grabbing industry-specific training information and circulated the information inside the group even if the training organiser designed it to randomly and equally select trainees from each ethnic group. Combined with the previous and current studies, some understandings of the Chagga ethnic group are acquired. Being an outsider and ethnic minority in Arusha City, maintaining the dominance in an industry that supplies local necessities is important for the Chagga ethnic group to survive in the disadvantaged milieu. Tightly cementing ethnic networks with business networks is one of Chagga's strategies to accomplish ethnic prosperity in the region. Thus, the Chagga ethnic group anchors a guard net to industry-specific information and knowledge for its ethnic members to secure its superiority over other groups.

Building and maintaining various and unimpeded channels of knowledge exchange explains industrial clusters' success (Goodman et al. 1989). Thus, suggestions for policymakers are to promote new entrants with diverse backgrounds to the industries and conduct specialised training courses. To avoid ethnic concentration, developing an ethnic product for ethnic minority MSEs is important. In addition, because capital constrains the strength of ethnic networks, establishing public professional facilities to upgrade the industry is necessary.

Lastly, some limitations of this study shall be raised and reconsidered in future studies. This study only observed technological skills of the cluster-based furniture producers 
in Arusha City; the possibility that Arusha clustered producers acquire their skills outside the clusters cannot be ruled out. The focus of this study is to highlight the disparity between ethnic majority and minority in cluster development. In terms of this, this study provides a piece of evidence for the significance of ethnic majority networking effect on knowledge learning in SSA and shows its limitation.

\section{Acknowledgements}

The author acknowledges JICA-RI for provision of data and thanks Prof. Todo from Tokyo University, and Prof. Tsunekawa from the National Graduate Institute for Policy Studies (GRIPS) for their concrete and helpful comments. I thank Dr Ku from Academia Sinica, Taiwan, and Dr Fuse from the National Institute of Population and Social Security Research for their technical help. However, this article reflects only my views and all errors are my own.

\section{Competing interests}

I declare that I have no financial or personal relationships that may have inappropriately influenced me in writing this article.

\section{References}

AlAzzawi, S., 2011, 'Multinational corporations and knowledge flows: Evidence from patent citations', Economic Development and Cultural Change 59, 649-680. https://doi.org/10.1086/658350

Audretsch, B., 1998, 'Agglomeration and the location of innovative activity', Oxford Review of Economic Policy 14, 18-29. https://doi.org/10.1093/oxrep/14.2.18

Braczyk, H.-J., Cooke, P. N. \& Heidenreich, M., 1998, Regional innovation systems: The role of governances in a globalized world, UCL Press, London.

Breschi, S. \& Lissoni, F., 2001, 'Knowledge spillovers and local innovation systems: A critical survey', Industrial and Corporate Change 10, 975-1005. https://doi. org/10.1093/icc/10.4.975

Brown, J. \& Duguid, P., 1991, 'Organizational learning and communities of practice: Toward a unified view of working, learning, and innovation', Organization Science 2, 40-57. https://doi.org/10.1287/orsc.2.1.40

Chung, C.Y.Y., 2018, 'Training effect of Japanese management on African SMEs: The case study on Japanese Kaizen training in Tanzania', Wseas Transactions on Business and Economics 15, 348-362.

Chung, W. \& Kalnins, A., 2001, 'Agglomeration effects and performance: A test of the Texas lodging industry', Strategic Management Journal 22, 969-988. https://doi. org/10.1002/smj.178

Conley, T.G. \& Udry, C.R., 2010, 'Learning about a new technology: Pineapple in Ghana', American Economic Review 100, 35-69. https://doi.org/10.1257/ aer.100.1.35

Crespo, J., Suire, R. \& Vicente, J., 2013, 'Lock-in or lock-out? How structural properties of knowledge networks affect regional resilience', Journal of Economic Geography 14, 199-219. https://doi.org/10.1093/jeg/lbt006

David, P.A. \& Rosenbloom, J.L., 1990, 'Marshallian factor market externalities and the dynamics of industrial localization', Journal of Urban Economics 28, 349-370. https://doi.org/10.1016/0094-1190(90)90033-J

Dustmann, C. \& Preston, I., 2001, 'Attitudes to ethnic minorities, ethnic context and location decisions', The Economic Journal 111, 353-373. https://doi.org/ 10.1111/1468-0297.00611

Easterly, W. \& Levine, R., 1997, 'Africa's growth tragedy: Policies and ethnic divisions', The Quarterly Journal of Economics 112, 1203-1250. https://doi.org/10.1162/ 003355300555466

Folta, T.B., Cooper, A.C. \& Baik, Y.-S., 2006, 'Geographic cluster size and firm performance', Journal of Business Venturing 21, 217-242. https://doi.org/ performance', Journal of Busines
10.1016/j.jbusvent.2005.04.005

Fukuyama, F., 1995, Trust: The social virtues and the creation of prosperity, Free Press Paperbacks, New York.

Goodman, E., Bamford, J. \& Saynor, P., 1989, Small firms and industrial districts in italy, Routledge, London.

Greif, A., 1993, 'Contract enforceability and economic institutions in early trade: The Maghribi traders' coalition', The American Economic Review 83(3), 525-548.

Harabi, N., 1997, 'Channels of R\&D spillovers: An empirical investigation of Swiss firms', Technovation 17, 627-635. https://doi.org/10.1016/S0166-4972(97)00064-3
Henderson, V., 1997, 'Externalities and industrial development', Journal of Urban Economics 42, 449-470. https://doi.org/10.1006/juec.1997.2036

Hoang, H. \& Antoncic, B., 2003, 'Network-based research in entrepreneurship: A critical review', Journal of Business Venturing 18, 165-187. https://doi. org/10.1016/S0883-9026(02)00081-2

International Labour Office (ILO), 2013, Global employment trends, International Labour Organization, Geneva.

Jaffe, A.B., Trajtenberg, M. \& Henderson, R., 1993, 'Geographic localization of knowledge spillovers as evidenced by patent citations', The Quarterly Journal of Economics 108, 577-598. https://doi.org/10.2307/2118401

Keller, W., 2002, 'Geographic localization of international technology diffusion' American Economic Review 92, 120-142. https://doi.org/10.1257/0002828 02760015630

Kelly, M. \& Hageman, A., 1999, 'Marshallian externalities in innovation', Journal of Economic Growth 4, 39-54. https://doi.org/10.1023/A:1009874508579

Kesidou, E. \& Romijn, H., 2008, 'Do local knowledge spillovers matter for development? An empirical study of Uruguay's software cluster', World Development 36, 2004-2028. https://doi.org/10.1016/j.worlddev.2008.01.003

Ketels, C., 2013, 'Recent research on competitiveness and clusters: What are the implications for regional policy?', Cambridge Journal of Regions, Economy and Society 6, 269-284. https://doi.org/10.1093/cjres/rst008

Kristiansen, S., 2004, 'Social networks and business success', American Journal of Economics and Sociology 63, 1149-1171. https://doi.org/10.1111/j.1536-7150. 2004.00339.x

Krugman, P., 1991, Geography and trade, MIT Press, Cambridge, MA.

Leigh, A., 2006, 'Trust, inequality and ethnic heterogeneity', Economic Record 82, 268-280. https://doi.org/10.1111/j.1475-4932.2006.00339.x

Li, W., Veliyath, R. \& Tan, J., 2013, 'Network characteristics and firm performance: An examination of the relationships in the context of a cluster', Journal of Small Business Management 51, 1-22.

Liang, Z., 1999, 'Foreign investment, economic growth, and temporary migration: The case of Shenzhen special economic zone, China', Development and Society 28, 115-137.

Marshall, A., 1920, Principles of economics, Macmillan, London.

Marshall, A. \& Marshall, M.P., 1920, The economics of industry, Macmillan and Company, London.

McCormick, D., 1999, 'African enterprise clusters and industrialization: Theory and reality', World Development 27, 1531-1551. https://doi.org/10.1016/S0305-750X reality', World
(99)00074-1

Mesquita, L.F., 2007, 'Starting over when the bickering never ends: Rebuilding aggregate trust among clustered firms through trust facilitators', Academy of Management Review 32, 72-91. https://doi.org/10.5465/amr.2007.23463711

Munshi, K., 2004, 'Social learning in a heterogeneous population: Technology diffusion in the Indian Green Revolution', Journal of Development Economics 73, 185-213. https://doi.org/10.1016/j.jdeveco.2003.03.003

Musteen, M., Francis, J. \& Datta, D.K., 2010, 'The influence of international networks on internationalization speed and performance: A study of Czech SMEs', Journal of World Business 45, 197-205. https://doi.org/10.1016/j.jwb.2009.12.003

Muto, M., Chung, C.Y.Y. \& Shimikoshi, S., 2011, Location choice and performance of furniture workshops in Arusha, Tanzania, Working Paper No.28, JICA, Tokyo.

Paci, R. \& Usai, S., 1999, 'Externalities, knowledge spillovers and the spatial distribution of innovation', GeoJournal 49, 381-390. https://doi.org/10.1023/A:1007192313098

Porter, M.E., 1990, 'The competitive advantage of nations', Competitive Intelligence Review 1, 14-14. https://doi.org/10.1002/cir.3880010112

Porter, M.E., 1998, 'Clusters and the new economics of competition', Harvard Business Review 76, 77-90.

Powell, W.W., Koput, K.W. \& Smith-Doerr, L., 1996, 'Interorganizational collaboration and the locus of innovation: Networks of learning in biotechnology', Administrative Science Quarterly 41(1), 116-145. https://doi.org/10.2307/2393988

Rivera, M.T., Soderstrom, S.B. \& Uzzi, B., 2010, 'Dynamics of dyads in social networks: Assortative, relational, and proximity mechanisms', Annual Review of Sociology 36, 91-115. https://doi.org/10.1146/annurev.soc.34.040507.134743

Schneider, F. \& Enste, D.H., 2000, 'Shadow economies: Size, causes, and consequences', Journal of Economic Literature 38, 77-114. https://doi.org/10.1257/jel.38.1.77

Shaver, J.M. \& Flyer, F., 2000, 'Agglomeration economies, firm heterogeneity, and foreign direct investment in the United States', Strategic Management Journal foreign direct investment in the United States', Strategic Management Journal 21(12), 1175-1193. https://
AID-SMJ139\%3E3.0.CO;2-Q

Sonobe, T. \& Otsuka, K., 2006, Cluster-based industrial development: An East Asian model, Palgrave Macmillan, Basingstoke.

Sorenson, O. \& Audia, P.G., 2000, 'The social structure of entrepreneurial activity: Geographic concentration of footwear production in the United States, 1940-1989', American Journal of Sociology 106, 424-462. https://doi.org/10.1086/316962

Stuart, T. \& Sorenson, O., 2003, 'The geography of opportunity: Spatial heterogeneity in founding rates and the performance of biotechnology firms', Research Policy 32, 229-253. https://doi.org/10.1016/S0048-7333(02)00098-7

Swann, G., Prevezer, M. \& Stout, D., 1998, The dynamics of industrial clustering: International comparisons in computing and biotechnology, Oxford University Press, Oxford.

Swenson, D.L., 2008, 'Multinationals and the creation of Chinese trade linkages', Canadian Journal of Economics/Revue canadienne d'économique 41, 596-618. 
The World Bank, 2004, World development report, World Bank, Washington, DC.

Todo, Y. \& Miyamoto, K., 2006, 'Knowledge spillovers from foreign direct investment and the role of local R\&D activities: Evidence from Indonesia', Economic Development and Cultural Change 55, 173-200. https://doi.org/ $10.1086 / 505729$
Von Hippel, E., 1988, Sources of innovation, Oxford University Press, New York.

Zaheer, S., Lamin, A. \& Subramani, M., 2009, 'Cluster capabilities or ethnic ties? Location choice by foreign and domestic entrants in the services offshoring industry in India', Journal of International Business Studies 40, 944-968. https:// doi.org/10.1057/jibs.2008.91 


\section{Appendix 1}

TABLE 1-A1: Ranking of assembly techniques.

\begin{tabular}{lcccc}
\hline Ranking & Wood & Screw & Nail & Glue \\
\hline 15 & X & - & - & - \\
14 & X & X & - & - \\
13 & X & X & X & - \\
12 & X & - & X & - \\
11 & X & X & - & X \\
10 & X & X & X & X \\
9 & X & - & X & X \\
8 & X & - & - & X \\
7 & - & $X$ & - & - \\
6 & - & $X$ & $X$ & - \\
5 & - & $X$ & $X$ & X \\
4 & - & $X$ & - & X \\
3 & - & - & $X$ & - \\
2 & - & - & $X$ & X \\
1 & - & - & - & X \\
\hline
\end{tabular}

Note: A higher ranking indicates a superior manufacturing technique. The ranks of 15 woodjoining techniques are listed with the rules: (1) joints including mortise joints which are ranked higher than those using screws; (2) joints including nails which always ranked below screwed joints; (3) joints with glue which are inferior to those using nails. 